\title{
Drogadicción y aislamiento social. Reflexiones sobre la atención a drogadictos en francia y Colombia
}

\section{Drugaddiction and Social Isolation. Reflections on Care Seruices for Drugaddicts in France and Colombia \\ Toxicomania e isolamento social. Reflexões sobre a atenção a toxicómanos na França e na Colômbia}

\author{
Jean-Luc Gaspard*, Silvia María Rivera Largacha** \\ ${ }^{*}$ Université de Rennes II, Francia. ${ }^{* *}$ Universidad del Rosario, Bogotá, Colombia
}

Doi: http://dx.doi.org/10.12804/apl34.2.2016.07

\section{Resumen}

Este artículo plantea una reflexión sobre el consumo de drogas y las propuestas de atención dirigidas a drogadictos en Francia y Colombia. Las conclusiones se basan en el análisis de datos cualitativos obtenidos mediante observaciones etnográficas y entrevistas semidirectivas. Las conclusiones muestran que, a pesar de la distancia cultural existente entre los dos contextos, ambos comparten elementos respecto a las manifestaciones de las dificultades que enfrentan los consumidores de drogas en su reintegración social. En el artículo se cuestiona por qué y para qué una intervención dirigida a estas poblaciones, a fin de dar claves para entender su eficacia o su fracaso, en particular cuando dichas propuestas integran los servicios de atención psicosociales y las propuestas de tratamiento médicas, algunas veces basadas en el uso de drogas de sustitución.

Palabras clave: drogadicción; lazo social; aislamiento social; sustitución de drogas; psicoanálisis.

\section{fbstract}

This article makes a reflection on drug consumption and care services for drug consumers in France and Colombia. Our conclusions are based on ethnographic observations and semidirective interviews. The findings show that despite the cultural distance between the two contexts, both share common elements concerning the manifestations of the difficulties faced by drug users in their social reintegration. Our aim is to question the why and the what for of interventions on these populations that could give keys to understand its effectiveness or its failure in particular when these care proposals integrate psychosocial care and medical intervention sometimes based on the use of substitution drugs.

Keywords: drug addiction; social links; social isolation; drug substitution; psychoanalysis.

* Jean-Luc Gaspard, director del laboratorio Investigaciones en Psicopatología Clínica; Prácticas Campos Específicos (EA 4050), Université Rennes 2, Place Recteur le Moal, 35043 Rennes Cedex, Francia; ** Silvia María Rivera Largacha, profesora principal de la Escuela de Medicina y Ciencias de la Salud de la Universidad del Rosario, Bogotá.

La correspondencia relacionada con este artículo debe ser dirigida a Silvia María Rivera Largacha, Escuela de Medicina y Ciencias de la Salud de la Universidad del Rosario, Bogotá. Colombia. Correo electrónico: silvia.rivera@urosario.edu.co

Cómo citar este artículo: Gaspar J-L. \& Rivera, S. M. (2016). Drogadicción y aislamiento social. Reflexiones sobre la atención a drogadictos en Francia y Colombia. Avances en Psicología Latinoamericana, 34(2), 315-338. doi: http://dx.doi.org/10.12804/ ap134.2.2016.07 


\section{Resumo}

Este artigo apresenta uma reflexão sobre o consumo de drogas e as propostas de atenção dirigidas a toxicómanos na França e na Colômbia. Nossas conclusões estão baseadas na análise de dados qualitativos obtidos através de observações etnográficas e entrevistas semi-diretivas. As conclusões mostram que a pesar da distância cultural existente entre os dois contextos, ambos os dois compartilham elementos comuns com respeito às manifestações das dificuldades que enfrentam os consumidores de drogas na sua reintegração social. Queremos questionar o porquê o para que de uma intervenção dirigida a estas populações, que possa dar chaves para entender a sua eficácia ou o seu fracasso, em particular quando ditas propostas, integram os serviços de atenção psicossociais e as propostas de tratamento médicas algumas vexes baseadas no uso de drogas de substituição.

Palavras-chave: toxicomania; laço social; isolamento social; substituição de drogas; psicanálise.

El artículo pretende elaborar una reflexión sobre el consumo de drogas y las propuestas de atención dirigidas a las poblaciones en condiciones de vulnerabilidad de dos países (Francia y Colombia) que culturalmente parecen distantes y que han tenido políticas de atención a consumidores de drogas muy diferentes. Nuestro trabajo está basado en observaciones etnográficas realizadas en centros de atención a consumidores de drogas en situación de vulnerabilidad. Esta metodología nos ha permitido reflexionar sobre las formas de funcionamiento particulares de cada contexto y ubicar lo que en cada uno de estos centros de atención puede dar cuenta del funcionamiento psíquico de sus usuarios.

Dentro de esta comparación se puede identificar cómo - a pesar de la distancia cultural existente entre ambos contextos - ambos comparten elementos comunes respecto a la forma como en ellos existen grupos de personas que, en un proceso de inmersión en el consumo de drogas, se encuentran aisladas por la imposibilidad de construir o resta- blecer lazos sociales que aseguren su supervivencia social, física y psíquica. Estas poblaciones han sido objeto de varios estudios en Francia: Damon (2012), Declerck (2005), Babin (2004), Douville $(2004,2012)$. En Colombia, fuera de los trabajos de psicoanalistas como Roelens (2001) y de Gutiérrez (1967, 1972, 2002), las investigaciones sobre estas poblaciones son escasas. Hay un estudio dirigido por la Alcaldía de Bogotá y financiados por la Cámara de Comercio de la misma ciudad (1997), y otro elaborado por la Alcaldía Mayor de Bogotá y la Pontificia Universidad Javeriana (2003).

Dentro de esta comparación, nuestro objetivo es identificar los elementos comunes que emergen dentro de las propuestas de atención a poblaciones vulnerables, cuya situación está atravesada por las dificultades que acompañan el abuso en el consumo de drogas. Se trata de abrir una reflexión sobre cómo la clasificación de estas personas en los planos médico, social y psicológico como "consumidoras problemáticas de sustancias psicoactivas" repercute en su posición subjetiva y, por lo tanto, en la forma en que participan en las propuestas de atención que en principio son diseñadas para facilitar su reintegración social. Esto tiene, por un lado, un interés sociológico, pues nos permite reflexionar sobre por qué y para qué una intervención psicosocial dirigida a estas poblaciones y, por otro, puede dar claves para entender su eficacia o su fracaso. En cuanto a la investigación en temas propios de la psicología y del psicoanálisis, este artículo tiene por objetivo identificar rasgos comunes dentro de una población diversa dentro de la cual las categorías clínicas propuestas, como drogadicción o toxicomanía, parecen insuficientes para identificar las particularidades de las complejas relaciones que se generan en torno al consumo de drogas.

\section{Diseño metodológico y muestra}

Las conclusiones traídas en este texto son el resultado de un trabajo de acercamiento a poblaciones consumidoras de drogas que carecen de 
un domicilio fijo y habitan generalmente en la calle. Se trabajó con una metodología mixta en la que se combinaron entrevistas de investigación con observaciones etnográficas. La elección de la muestra se hizo teniendo en cuenta los criterios teóricos de Patton (1990) para la elección de una muestra representativa de informantes clave que dentro de los centros de atención a consumidores de droga tuvieran información privilegiada sobre las representaciones sociales del consumo de drogas, de la relación con el cuerpo y del funcionamiento institucional de estos centros.

En el caso de Francia, los testimonios de estas personas fueron recogidos en la ciudad de Toulouse dentro de un centro de atención que funciona a partir del diseño de estructuras de atención establecidas en el ámbito nacional y que se han denominado Centros de Acogida y de Acompañamiento a la Reducción de Riesgos para los Usuarios de Drogas (Caarud, por su sigla en francés). Estas estructuras están abiertas a personas que reconocen tener dificultades con el consumo de drogas; pero que no demandan ningún tipo de cura o proceso de desintoxicación, es decir, acuden a estas instituciones sin solicitar intervenciones de parte del equipo que pudieran estar orientadas a ayudar a la persona a disminuir o a evitar el consumo de drogas. Los Caarud funcionan desde el modelo de la reducción de riesgos y fueron creados en el 2006, en el contexto de una política de salud pública cuyo objetivo era reducir los riesgos y los daños sanitarios y sociales asociados al consumo de productos psicotrópicos; estos centros son financiados por el sistema de seguridad social y acogen gratuitamente a los usuarios.

Estas estructuras se especializan en la atención básica de necesidades de alimentación e higiene y, en algunos casos, la distribución de Metadona ${ }^{\circledR}$, el tratamiento farmacológico encaminado a disminuir en los consumidores de opiáceos los signos del síndrome de abstinencia. Este tratamiento distribuido en los Caarud no implica una obligatoriedad de otro tipo de acompañamiento psicosocial. Para el caso de Colombia, los testimonios fueron recogidos en la ciudad de Bogotá en estructuras llamadas Hogares de Paso, lugares cerrados en los que los usuarios son admitidos durante tres meses bajo la condición de responder a las exigencias de comportamiento establecidas por la institución, particularmente la evitación del consumo de sustancias. También en estos centros la atención al usuario es gratuita, pero en este caso es financiada por el Gobierno distrital, particularmente por la Secretaría de Integración Social.

En ambos casos, los equipos de investigadores dedicaron varias jornadas de observación durante tres semanas en cada espacio. Estas observaciones etnográficas tuvieron como objetivos: primero, recoger información sobre el modo de funcionamiento de estos espacios y sobre las representaciones sociales respecto al consumo de drogas y respecto a las relaciones que los sujetos usuarios de estos centros establecen con su propio cuerpo. Para ello se hizo un seguimiento de los referentes simbólicos que se hacían evidentes en el lenguaje de los usuarios y los profesionales de los equipos de trabajo, pero también dentro de las prácticas y las formas de interacción social. El segundo objetivo del trabajo etnográfico fue familiarizar a la población con los equipos de investigación y, a partir de ello, generar confianza para posteriormente plantear a algunas personas de manera puntual el participar en entrevistas basadas en un cuestionario semidirectivo, que abarcaba un recuento de la historia personal, preguntas sobre la relación con su propio cuerpo, que de manera inevitable conducían siempre al tema del consumo de drogas y de la relación del sujeto con el centro de acogida en el que era encontrado por el equipo de investigadores.

Aunque los estudios etnográficos suelen tener periodos de observación más largos, para el caso de este trabajo las condiciones de los espacios hicieron que el tiempo destinado fuera suficiente. Por tratarse de habitantes de calle, la población encontrada era supremamente itinerante y en tres semanas se podía ver en ambos casos una alta 
rotación de las personas que acudían a los centros de atención. Tanto en los Caarud como en los Hogares de Paso se entrevistaron una decena de personas (cinco hombres y cinco mujeres en cada centro). Por otro lado, dentro del material recogido se tuvieron en cuenta también datos obtenidos de los equipos de trabajo encontrados en cada una de estas estructuras. En el caso de Colombia, se hicieron entrevistas con el director del Hogar de Paso y con funcionarios de apoyo que trabajaban en este. La escasez de tiempo de parte de los profesionales fue la mayor dificultad para lograr obtener información por esta vía. Por el contrario, en el caso de los Caarud obtuvimos información de primera mano, al consultar los documentos de descripción de las reuniones del equipo de profesionales del centro con un supervisor externo al centro, que se organizan semanalmente. En estas reuniones se habla sobre el funcionamiento general del centro y sobre los casos exitosos o problemáticos que se van dando a lo largo de cada semana. Estas reuniones se dan con un psicólogo de orientación psicoanalítica externo al centro que acompaña al grupo de profesionales a tomar distancia y analizar de manera detallada los incidentes que se presentan en el lugar. Estos documentos fueron utilizados con previa autorización del equipo y de las directivas del Caarud. Para complementar esta información recolectada utilizamos también los diarios de campo y entrevistas de una observación etnográfica que uno de nuestros investigadores realizó durante julio del 2013 en la Corporación Cachivache.

La información obtenida se analizó a partir de la metodología de análisis del discurso, en que se utilizan transcripciones de los encuentros con los participantes, cuya duración promedio era de una hora. Dentro del análisis de las entrevistas, de los diarios de campo donde se consignaron las experiencias etnográficas y de los apuntes de las reuniones de equipo del Caarud se planteó una forma de análisis cimentada en los principios del psicoanálisis, es decir, se hizo un esfuerzo por encontrar los contenidos inconscientes que se ponían de manifiesto en las declaraciones de los participantes, pero también en sus actitudes y sus formas de interacción. Desde esta óptica, se privilegiaron las referencias con respecto a las representaciones sociales sobre la dependencia a las drogas, el uso del cuerpo y el funcionamiento institucional de los centros de acogida que se construyen en los discursos, las actitudes y las prácticas de los actores encontrados.

\section{El monosíntoma dentro de la investigación clínica}

El lazo social contemporáneo está caracterizado cada vez más por formas de relación en las cuales se exacerba la rivalidad entre los individuos y donde cada uno se ve obligado a participar dentro de una carrera desenfrenada por obtener lo que Lacan llama el plus de goce (Lebrun, 2009), que hace referencia a una experiencia de satisfacción que fácilmente desconoce las necesidades de los otros.

La obnubilación del individuo con respecto al consumo desenfrenado y la búsqueda de satisfacción han reversado las perspectivas clínicas clásicas y exige, para los actores en el campo social, repensar los dispositivos de atención del sufrimiento psíquico (Gaspard, 2014). Desde este punto de vista, se han creado nuevas modalidades particulares de atención a las problemáticas actuales (depresión, trastornos del comportamiento alimentario, adicciones), es decir, lo que hoy en día en la investigación clínica de orientación psicoanalítica se ha llamado clínica del monosíntoma (Recalcati, 2005). Esta categoría hace referencia a una situación paradójica en la que el sujeto sufre por la imposibilidad de desprenderse de lo que parecería el objeto de su sufrimiento (tristeza generalizada, dificultad en su relación con la comida o con el consumo de sustancias psicoactivas); pero, a su vez, encuentra una serie de ganancias e incluso cierta satisfacción en la identificación con sus dificultades o con la nominación de estas dentro de una categoría patologizante y generalizante. 
Así, dentro de la constitución del monosíntoma, el sufrimiento del sujeto, diríamos en términos psicoanalíticos, ya no hace síntoma, es decir, ya no representa "lo más particular del sujeto". Dentro de las proposiciones del psicoanálisis, particularmente en la lectura lacaniana del síntoma, este es la forma particular como el sujeto da cuenta de su forma propia de encontrarse un lugar en el mundo. El psicoanálisis es un escenario propicio para que cada persona pueda encontrar esta forma particular de relacionarse con el mundo, que muchas veces inicia por un comportamiento "indeseable" que, al ser analizado, devela su sentido inconsciente y puede perder vigencia dentro del comportamiento general del sujeto. Sin embargo, cuando el comportamiento del sujeto entra dentro de la dinámica del monosíntoma, esta posibilidad se ve limitada y el síntoma se convierte en un sistema hermético, reticente a cualquier interpretación, lo cual dificulta la posibilidad de que el sujeto logre encontrar lo particular de aquello que lo hace sufrir y genera en este una asimilación y una identificación radical con una denominación patológica o con un producto. El monosíntoma, en vez de ser una solución singular e inconsciente de la relación del sujeto con el Otro, ${ }^{1}$ sirve acá de respaldo a la promesa ilusoria de borrar definitivamente la falta-en-ser estructural.

El monosíntoma viene así a garantizar una identidad y a disminuir al sujeto a un rasgo único (para el caso de la drogadicción, su lazo con las drogas). La particularidad se encuentra velada por una especie de discriminación, de segregación organizada, donde todo un "discurso de especialistas" disuelve la verdad del sujeto en una adhesión excesiva a la norma social y donde el sujeto, excluido finalmente

1 Dentro de las categorías lacanianas, el Otro con mayúscula hace referencia a la concepción de lo externo al sujeto. Se trata de un término que describe todo aquello que para cada sujeto representa la alteridad. Dentro de esta alteridad, cada sujeto incluye los significantes y significados que le vienen de su relación con sus allegados, pero también con desconocidos con su contexto social general y con las representaciones sociales y las actitudes que lo rodean y que percibe de manera consciente o inconsciente. por su particularidad, busca "normalizarse", es decir, encontrarse un lugar social por la relación con un grupo patologizado y estigmatizado. Para el individuo obeso, anoréxico, depresivo, adicto, alcohólico, existe un estado de los afectos o un objeto (para el caso de la drogadicción la droga) que sirve en un inicio como un elemento que anula o desvanece los efectos de la confrontación del sujeto a la castración o a la falta. ${ }^{2}$ Los efectos producidos por las drogas o el objeto droga en sí representan una especie de avatar del sujeto. En el caso de la dependencia a las drogas, este avatar no tiene que ser necesariamente una droga ilegal. Muchas veces, incluso, un tratamiento farmacológico o de sustitución puede ocupar este lugar. Los tratamientos de sustitución consisten en tratamientos farmacológicos basados en investigación y referencias neurobiológicas que tienen como objetivo la recuperación de los pacientes farmacodependientes, al producirles una disminución de los síntomas propios del síndrome de abstinencia, por medio de la administración de una sustancia que posee propiedades farmacológicas similares a las de un psicotrópico adictivo.

\section{La drogadicción como formación monosintomática}

Entre las formaciones monosintomáticas propias de la modernidad, la drogadicción parece paradigmática (Askofaré \& Sauret, 1998), dado que la droga (sea o no de sustitución) a la cual el sujeto se identifica se sitúa como uno de los elementos más importantes de su relación con el mundo (Gaspard,

2 Dentro del modelo lacaniano, la castración o la falta hace referencia a la confrontación del sujeto a las limitaciones típicas que impone la vida y a la frustración que estas representan frente a la tendencia del sujeto a obtener una satisfacción inmediata de sus deseos. Esta frustración y la manera como el sujeto se las ve con las limitaciones que le impone la vida son el espacio donde le es posible reconocer las necesidades $\mathrm{y}$ deseos de quienes lo rodean y establecer construcciones imaginarias y simbólicas que le permitan lidiar con la frustración y reconocer y convivir con otros. 
2007). Sin entrar en el debate sobre la existencia o no de una estructura de personalidad particular al drogadicto (Bergeret, 1982), podemos señalar de qué forma Zafiropoulos (1988) define el consumo problemático de drogas como un fenómeno propio de una pluralidad de posiciones subjetivas en relación con cualquiera de las estructuras reconocidas dentro de la psicopatología psicoanalítica (neurosis, psicosis o perversión).

En el plano clínico, la drogadicción es una problemática donde la queja del sujeto, que se confronta a la división subjetiva y a la falta-enser, ${ }^{3}$ se revela comúnmente junto con una interferencia, "una uniformización, producida por la práctica de la droga, que impide la identificación de una estructura" (Aucremanne, 1990, p. 62). Frecuentemente, la drogadicción hace manifiesta una relación paradójica con el Otro (Rivera-Largacha $\&$ de Neuter, 2008), que consiste en que el sujeto, al hacer uso de las drogas, revela una forma de relación problemática con el Otro. Por un lado, el sujeto encuentra una satisfacción en las sensaciones desbordantes obtenidas en el consumo de drogas. Dentro de la terminología psicoanalítica, esto se puede entender como una forma de goce ${ }^{4}$ arcaico que Lacan llama goce uno (característico de las primeras modalidades de relación con el Otro en las cuales el sujeto experimenta una dependencia total respecto a la presencia de un alguien del que depende su existencia).

A pesar de esta tendencia, dentro del consumo de drogas que toma la forma de una drogadicción, el sujeto estaría orientado al mismo tiempo por

3 Estas expresiones lacanianas hacen referencia a los efectos de malestar e incluso de angustia que se hacen manifiestos en el sujeto en situaciones donde se hace frente a la vulnerabilidad y a la incompletud propias.

4 Dentro del modelo lacaniano, la categoría de goce se refiere a las diferentes relaciones con la satisfacción y la frustración que un sujeto, que habla y que está marcado por la dimensión del deseo, puede esperar o experimentar al hacer uso de un objeto. El goce no es un equivalente del placer, sino que por el contrario describe la delgada línea que separa el placer y el displacer. la idea de evitar el uso de estas sustancias. Sin embargo, la pérdida del sujeto en el goce que le procura el consumo y, de este modo, su sumisión a las modalidades más arcaicas del Otro dan como resultado una condición paradójica: el sujeto se pone en una situación de sumisión frente a aquello que es más primitivo del Otro, pero a la vez se rebela contra esta misma figura. Esta rebelión se dirige generalmente hacia las versiones menos primitivas de esta figura, es decir, el sujeto se rebela frente a esas versiones del Otro que se van adquiriendo en momentos posteriores de la vida del sujeto y que imprimen en él los elementos simbólicos que hacen posible una interacción con sus semejantes. La generalización en el rechazo al Otro de parte del sujeto, tanto en sus versiones más arcaicas como en sus versiones tardías, interfiere en la capacidad del sujeto por tener acceso a elementos simbólicos a partir de los cuales podría encontrarse un lugar dentro del mundo de lo humano. Al rechazar de manera tajante la figura del Otro, el sujeto renuncia a diversas formas de alteridad que le permitirían inscribirse dentro del lazo social.

En estas condiciones es determinante defender una clínica diferencial a partir de las particularidades del sujeto; no obstante, para ello es necesario llevar a cabo una reflexión profunda sobre el consumo de productos cuando dicha práctica está rodeada por la miseria y las rupturas subjetivas.

\section{Descripción y reflexiones sobre la atención a las poblaciones de consumidores de drogas en Francia y en Colombia}

Cuando el consumo de drogas está asociado a la vulnerabilidad social y psíquica es necesario abrir proposiciones que hagan posible el encuentro clínico. Desde esta perspectiva, existen en Francia los Caarud que, como ya lo hemos explicado dentro de este texto, son estructuras abiertas a drogadictos que no demandan ningún tipo de tratamiento de desintoxicación o de cura respecto su relación problemática con las sustancias. 
Estos centros de acogida, donde puede iniciarse la reducción de riesgos y de problemas de salud ligados al uso de las drogas, constituyen un primer paso en la clínica del monosíntoma. La particularidad de tales estructuras está en favorecer la recreación de un lazo social al brindar a sus usuarios un acceso mínimo a una atención en salud. Los Caarud son espacios que permiten a los usuarios de drogas reencontrar una dignidad, un lugar en la ciudad. Estos sitios se presentan como espacios intermedios particulares, puesto que es innecesario tener la intención de parar el consumo de productos o de tener alguna demanda específica para tener contacto con los profesionales que trabajan allí. Una oferta de este tipo, sin embargo, no está exenta de ubicar al equipo de trabajo ante situaciones delicadas como consecuencia de los problemas que se presentan entre los usuarios del Caarud y entre los usuarios y el equipo de profesionales, que son trabajadas regularmente dentro de las reuniones del equipo de profesionales, quienes en compañía de un psicólogo-psicoanalista externo a la institución hacen un trabajo de supervisión en el que en conjunto se elabora un análisis institucional que les permita develar cuál es el sentido que se revela en las situaciones de conflicto en el interior del centro.

El modelo de los Caarud contrasta con las ofertas de atención que se han implementado en Colombia, país donde las políticas de salud pública referentes al consumo de drogas se inscriben en su mayoría dentro de una lógica de control policiaco que dan como resultado ofertas de atención que proponen resultados a corto plazo y cuyos objetivos se reducen a la utópica búsqueda de una erradicación inmediata de todo consumo. Dichas propuestas difícilmente tienen en cuenta la complejidad de la situación de los consumidores problemáticos de drogas, en especial aquellos con largas historias en el uso de estos productos, historias que en ocasiones se inician desde la infancia. Estas políticas pasan por alto la necesidad de ofrecer a este tipo de personas un acompañamiento de largo plazo que asegure una mínima reestructuración o una construcción de los lazos sociales perdidos o jamás adquiridos.

Al no existir una política nacional homogénea de atención a este tipo de población, nos dedicaremos a describir las ofertas de atención abiertas dentro de la ciudad de Bogotá impulsadas por el Gobierno distrital. Los Centros de Atención en Drogadicción (CAD), conocidos posteriormente en Bogotá como Hogares de Paso, son estos lugares cerrados en los que, como ya lo hemos explicado, los usuarios son admitidos durante tres meses bajo la condición de responder a las exigencias de comportamiento establecidas por la institución, particularmente a la obligación de evitar cualquier consumo de sustancias durante este periodo.

A diferencia de los Caarud, estos lugares no funcionan a partir de una intención clara de reducir riesgos y daños. El discurso dominante identifica la drogadicción como una dificultad social y como una enfermedad que debe ser curada en los términos de una erradicación del síntoma. Estos centros prestan servicio gratuito a sus usuarios, y a pesar de la importante inversión destinada a su funcionamiento, los recursos son insuficientes para acoger a la gran cantidad de usuarios potenciales de este servicio. El censo de habitantes de calle en Bogotá del 2008 identificó 8385 personas, entre las cuales una proporción importante presenta dificultades ligadas al consumo de drogas.

En estas condiciones, los recursos destinados para estas poblaciones son orientados hacia las necesidades básicas de alimentación e higiene. Las intervenciones clínicas o, incluso, los espacios de palabra ofrecidos por los profesionales que allí trabajan se convierten en un privilegio reservado a una minoría.

En estas condiciones, es imposible generar en la atención cotidiana, una aproximación clínica que tenga en cuenta la particularidad de los usuarios y particularmente de las dificultades que estos tienen dentro del consumo de drogas. Además, con frecuencia, las intervenciones de los profesionales de los hogares de paso tienen una eficacia muy 
limitada para hacer frente a las condiciones de segregación y de desigualdad social tan complejas que afectan a esta población. Dentro de las entrevistas realizadas a los usuarios de estos centros pudimos encontrar a muchos de ellos que veían su estadía en el hogar de paso solo como un periodo de reposo dentro de las difíciles condiciones que les impone la vida de calle. Para estas personas la indigencia es vista como un destino ineludible, ya que no cuentan con recursos sociales, educativos o económicos para cambiar sus condiciones de vida. A esto se añaden las exigencias que impone sobre ellos la necesidad de consumir drogas que se suma a la lista de factores que impiden una búsqueda activa por encontrar recursos que les permitan salir de la vida de calle.

Los Hogares de Paso ofrecen un tratamiento de desintoxicación durante tres meses, en el cual el único protocolo que parece aplicarse es el simple aislamiento del usuario de la vida de calle y de su contacto con las drogas, junto con algunos talleres que una o dos veces al día ocupan su tiempo. A la salida de estos lugares no existen para los usuarios ofertas de seguimiento, ni un sistema de apoyo o formación. Así, estos centros terminan siendo frecuentemente lugares donde se refuerza una identificación de los usuarios con la figura socialmente estigmatizada del drogadicto. Al aceptar esta condición de abandonar todo consumo de drogas para ingresar al centro, de manera implícita los usuarios ponen la droga como un elemento central, si no el más importante, dentro de las dificultades de su vida. De esta forma, encuentran en el marco institucional un escenario que refuerza la lógica del monosíntoma.

Como contraste de esta oferta oficial, en el ámbito privado se han creado diferentes propuestas de atención a habitantes de calle, generalmente inscritas dentro de la misma lógica de erradicación del síntoma sostenida desde un lenguaje policiaco, medicalizado o una lógica doctrinal. En contraste, existió en Bogotá durante casi quince años una experiencia que vale la pena resaltar: la Corporación
Cachivache, cuyas acciones se dirigieron especialmente a personas jóvenes, incluso niños habitantes de calle. Esta experiencia fue creada dentro de una lógica más próxima a aquella que hoy en día se encuentra en los Caarud en Francia. En ambos espacios se trata de lugares intermedios cuyo objetivo es reconstituir los lazos sociales perdidos o jamás establecidos por los usuarios. La propuesta de Cachivache era establecer y ofrecer al sujeto una distancia respecto a la violencia del cotidiano de la vida de calle. A diferencia de los Caarud, la Corporación Cachivache no estaba centrada en el problema del consumo de las drogas, puesto que esta práctica se entendía como parte de un cuadro propio de personas que se encontraban en una situación social de aislamiento y de abandono, donde el consumo de drogas era solo uno de los múltiples componentes de una realidad compleja.

La Corporación Cachivache abrió sus puertas en 1994 para acoger a habitantes de la calle que eran muy frecuentemente consumidores de drogas (en especial el pegante y el bazuco). La población de habitantes de calle en Bogotá siempre ha sido supremamente heterogénea. El trabajo de esta asociación es descrito por su fundadora, en las siguientes palabras:

[...] el objetivo no es ni la rehabilitación, ni la formación ni la ocupación. No es un lugar terapéutico, tampoco es un auspicio para indigentes; su objetivo es otro. Cada uno es invitado a hacer aquí lo que vino a hacer o a decir. Cada quién descubre una acogida abierta a sus demandas, un gesto que reconforta, cuidados para el cuerpo herido. No damos ni comida, ni vestido ni plata. No los sometemos tampoco a largas entrevistas: ¿para qué hablar cuando no se tiene nada? ¿Para exponer aún más la realidad de un abandono, de la soledad, de la violencia? ¿Para agravar la falta? [...] la palabra se libera cuando ellos tengan confianza y cuando no se sientan acosados por una mirada que se dirige sobre esa división subjetiva hecha de fracasos, de caídas, de delitos, de heridas profundas al narcisismo; 
ellos descubrirán el placer de un encuentro diferente, ellos podrán entonces dejar de lado el cuerpo acorazado, el disfraz de ñero, ${ }^{5}$ la exigencia de una satisfacción inmediata (Roelens, 2001, p. 121).

En este aspecto, por el tiempo y la lentitud que toma la articulación de la palabra, los Caarud tienen también un funcionamiento similar al que era manejado en la Corporación Cachivache. La población acogida puede venir durante días o semanas, incluso meses, sin comprometerse con la palabra. Esta falta de compromiso con aquello que justamente podría establecer una apertura a una cura psíquica es reemplazada por una atención mínima a pequeños gestos del "cuidado de sí mismo" más elemental: intercambio de jeringas, ducha, lavado de ropa, comer una colación, visita a la enfermería.

Es necesario referirse a las particularidades de la clínica para admitir que la relación con el lenguaje en un gran número de las personas acogidas en estos Caarud está generalmente perturbada. Esta misma observación, en cuanto a la relación con el lenguaje, la hace Roelens para el caso de la población acogida en Bogotá dentro del proyecto de Cachivache. En sus observaciones de los jóvenes de la calle de Bogotá, Roelens describe un cuestionamiento permanente del valor de la palabra como posibilidad de encontrar en el Otro un garante. El abandono que han enfrentado estos jóvenes es, según Roelens, es una de las causas de esta desconfianza frente a "la invitación a hablar". Dentro de las entrevistas de investigación realizadas en los hogares de paso de esta misma ciudad, esta relación problemática con el lenguaje también se hizo evidente.

En los tres espacios de atención que hemos mencionado en este texto (Caarud, Hogares de Paso y Corporación Cachivache), los profesionales que encontramos dieron cuenta de dificultades que muchos de los usuarios presentan al hablar de sí.

5 Expresión popular entre los habitantes de calle de Bogotá para hacer referencia al compañero, al amigo.
Generalmente, las referencias de los usuarios de estos centros difícilmente van más allá de algunos comentarios estereotipados. También se observan discursos repetitivos, una especie de logorreas que indican una carencia de singularización del discurso, es decir, una dificultad para hablar de sí mismos más allá de ciertas identificaciones con la estigmatización de la figura del habitante de calle o la del drogadicto.

En las observaciones hechas en los tres lugares se revela una posición paradigmática dentro de la drogadicción, a saber: una relación problemática con el lenguaje y la reducción del uso de las palabras a la expresión de demandas materiales con el fin de satisfacer las necesidades del momento. En los Caarud, en este caso, los profesionales saben que la presencia de los usuarios en este lugar excede siempre la satisfacción concreta de las necesidades elementales. Al entrar en este espacio, los usuarios están obligados a establecer una relación con el Otro, por la mediación de un tercero (usuarios o profesionales del centro) en una referencia constante a la institución y a la ley. El renunciar por unos minutos o unas horas a la vida de calle, confronta al sujeto a los límites que impone la institucionalidad del Caarud y que representa la institucionalidad y la ley del mundo que no está regido por la violencia y las contingencias de la vida de calle.

De este modo, van a presentarse desviaciones y transgresiones sobre esta zona fronteriza que luego pueden ponerse en palabras. Frecuentemente, el goce se revela, sea en una escenografía eruptiva hecha de expresiones delirantes, de disputas, de insultos, como en demostraciones que toman lugar en el cuerpo. Por ejemplo N, a quien le han abierto el vientre por una puñalada y que exhibe su cicatriz, o D, flaca y en un estado de negligencia absoluta, pasa todos los días a buscar kits de inyección para poderse drogar en la calle. ${ }^{6}$

6 Dentro de las propuestas de atención a los problemas de consumo de drogas bajo la modalidad de la disminución de riesgos, en Francia y en otros países, se distribuyen instru- 
Así mismo, regularmente los profesionales que trabajan allí son cuestionados y confrontados por comportamientos de falta de civismo que presentan los usuarios alrededor de las instalaciones del centro, así como protestas frecuentemente agresivas de parte de los usuarios cuando se ha agotado el pan, el jugo, entre otros. De allí la idea propuesta dentro del equipo de trabajo para evitar que el uso del lugar se reduzca a la simple función utilitarista. Dentro del equipo se hace claro que la manera de lidiar con las exigencias de los vecinos para con el centro y la manera de manejar las exigencias de parte de los usuarios no es la de responder de manera inmediata y eficaz a sus demandas ni blindarlos contra las críticas del entorno. De esta forma, la propuesta ha sido que de cuando en cuando exista la posibilidad de que algo falle, falte o no funcione; en últimas, se trata de no replegar la demanda de los usuarios a la necesidad respondiendo de manera inmediata, sino postergando la satisfacción para que surja en ellos la necesidad de hablar, sea para dar cuenta de sus comportamientos frente a la comunidad que rodea el centro o sea para señalar las fallas posibles en el sistema de atención. Se trata de dar lugar a la palabra. De lo contrario, la práctica de la alimentación y la oferta de otros servicios podría convertirse (si no se toman precauciones) en una solución defensiva y el uso del espacio se restringiría únicamente a un funcionamiento consumista que se reduce a una simple prestación de servicios, como parece ser el caso de los hogares de paso de la ciudad de Bogotá. En estos espacios, los recursos se invierten principalmente en solucionar los problemas inmediatos de alimentación y sostenimiento de los usuarios y los espacios de palabra son muy escasos. La oferta de atención en estos lugares se restringe a una acogida de tres meses durante los cuales la persona ve satisfechas sus necesidades básicas, para luego salir a la calle

mentos de inyección esterilizados y desinfectados que sirven a los usuarios de drogas, para tomar medidas de precaución contra enfermedades contagiosas. sin ningún acompañamiento psicosocial. En las entrevistas de investigación y en la observación realizada dentro de estos espacios era muy frecuente encontrar dentro del discurso de los usuarios un relato donde se revelaba cómo el lugar de paso se asumía no como un espacio de recuperación que permitiría un cambio en la forma de vida, sino como un espacio de descanso para aquellos que se encontraban agotados por las contingencias de la vida de calle; pero que sabían que iban a volver inevitablemente a estas circunstancias.

En los Caarud y los Hogares de Paso, los 1lamados usuarios presentan un gran polimorfismo sintomático: indigencia, alcoholismo, tabaquismo mayor, politoxicomanías, trastornos mentales, malnutrición, negligencia y falta de sueño. En el plano psicosocial, existe en ellos desinterés o incapacidad en la búsqueda de atención médica. Particularmente, en el caso de los usuarios en Bogotá este desinterés o incapacidad se agrava por las barreras que existen en el sistema de salud para que estas personas accedan a servicios médicos.

Varios de ellos, sobre todo en el caso de Francia, han pasado por unidades psiquiátricas (estados maniacos, delirios crónicos, estados melancoliformes, depresiones o por experiencias de desintoxicación). En los Caarud, la clientela más frecuente está conformada por personas que combinan diferentes tipos de drogas (alcohol-tabaquismo, drogas duras, psicotrópicos, ansiolíticos e, incluso, drogas de sustitución como el Subutex y la Metadona). En el caso de los usuarios de los hogares de paso de Bogotá también se observa una combinación frecuente de drogas diversas, aunque la combinación suele ser entre alcohol, bazuco y pegante. Así mismo, entre esta población heterogénea en ambos países encontramos sentimientos de insuficiencia, de culpabilidad, de autodesprecio, ligados a una trayectoria de precariedad y de exclusión (La Rosa, 1998; Parizot, 2003).

La búsqueda de un reconocimiento mínimo, la preocupación por pertenecer a una comunidad o el simple hecho de escapar por un momento de la 
indigencia diaria llevan a esta población a frecuentar los locales del Caarud. Los Hogares de Paso en Bogotá parecen ocupar, en cambio, una función de pausa, que en la mayoría de los casos se asume como temporal.

A diferencia de las estructuras de bajo umbral, como los Caarud, propuestas en Francia, en los Hogares de Paso las oportunidades de establecer identificaciones y de gozar de un reconocimiento individualizado son bastante limitadas, dada la gran cantidad de personas que a diario rotan por este tipo de estructuras y la escasez de personal proporcional al número de usuarios.

\section{La problemática del drogadicto en el uso del cuerpo}

Dentro de la diversidad de personas y de trayectorias de vida que se pueden ver en ambos tipos de estructura (Caarud y Hogares de Paso) se desprenden, sin embargo, una cantidad de puntos comunes para tener en cuenta en la práctica clínica con drogadictos. Entre la población atendida en ambos contextos se encuentra: una sucesión de traumas precoces, experiencias infantiles marcadas por la ausencia de la función de holding (Spitz, 1968), anomia y una relación problemática con la ley. Sobre todo, se resalta en la mayoría de casos la existencia de una problemática narcisística. Olievenstein (1982) sostiene la hipótesis de que es posible describir la experiencia del drogadicto como la de una imagen especular no unificada, despedazada, fisurada, que se compara con la de un espejo roto. Esta dificultad en la constitución de una imagen unificada en el sujeto tendría por consecuencia una situación de imposibilidad de parte de este para lograr una separación en principio, respecto a un objeto primario, que en la trayectoria del drogadicto se reemplazaría por el objeto droga.

La falla en los procesos de construcción narcisística del sujeto (identificación simbólica y estadio del espejo) produce una articulación deficitaria de lo imaginario del cuerpo y del registro simbólico.
El resultado es una relación particular con el cuerpo, caracterizada, en los casos más graves, por una indiferenciación de las zonas corporales; como si el sujeto hubiese desertado de su propio cuerpo.

Esta fenomenología del cuerpo "maltratado" nos conduce a la constatación hecha por Babin en su estudio sobre las vivencias de los habitantes de calle en Francia que se aplica igualmente a la población observada en Colombia:

Lo que nos parece más inquietante aún, que aparece, es visible y reconocible en la imagen física que estos hombres y estas mujeres presentan y que da testimonio de una destrucción, es que esta humillación mortífera que les ha sido infringida antes de que ellos prolonguen indefinidamente sobre ellos mismos el gesto asesino y aniquilador (Babin, 2004, p. 19).

Como subraya Lacan (1975-1976), el hombre tiene un cuerpo y solo uno. Sin embargo, hacer uno (lograr un sentimiento de unidad corporal) no es evidente, y esto obedece a un principio de articulación. Para darle consistencia al cuerpo y, en últimas, a lo humano, es necesario que exista un anudamiento entre las dimensiones de lo Real, de lo Imaginario y de lo Simbólico. En ausencia de ello, el riesgo es la partición, el despedazamiento, "un cuerpo que se parte en pedazos, que se fuga". El cuerpo posee otra cualidad que da consistencia a lo humano: está hecho para gozar de sí mismo (Hellebois, 2008, p. 6). En otras palabras, cada sujeto puede hacer uso particular de su cuerpo respecto al goce, para dar cuenta, incluso a través del síntoma, de la particularidad del goce que le es propio a cada sujeto. Muchas veces la manera de gozar (de hacer usufructo) de su cuerpo para el drogadicto se restringe a una serie de comportamientos que obedecen a un masoquismo erógeno. También sucede que el sujeto usa su cuerpo pulsionalmente. Lejos de ser mudo, el cuerpo habla a partir de la pulsión (como vínculo entre lo psíquico y lo somático). El goce puede ser entonces frenético, 
romper el cuerpo y desplegarse en un crecimiento mortífero. Cuando el anudamiento entre lo Real, lo Simbólico y lo Imaginario (RSI) no es seguro o se rompe, el exceso de goce produce una tensión extrema dispersa sobre el cuerpo entero. Se da entonces la exclusión del sentido (desacoplamiento de lo simbólico), el despliegue de lo imaginario y de esa figura de superyó arcaico que Lacan llama saboteador interno y que se manifiesta sobre la forma del imperativo categórico: “¡Goza!”.

Dentro de los estudios de la clínica psicoanalítica, se ha coincidido en asociar las deficiencias de las primeras relaciones objetales y las dificultades del orden especular y narcisista con la precariedad de los cimientos yoicos que suele ser un terreno abonado para la aparición de las drogadicciones. En estas condiciones, el sujeto encuentra un recurso, una muleta, un sustento en el consumo de sustancias. En comparación con la clínica del alcoholismo, la drogadicción revela una diferencia específica en cuanto a las relaciones objetales que están en su origen. El alcoholismo se explica como una dificultad dentro de la unificación del cuerpo, situada particularmente en la oralidad, como rastro del destete y, por lo tanto, en la relación con lo materno; en cambio, el consumo de drogas estaría principalmente articulado a la cuestión de la relación con la ley del padre. La drogadicción sería una tentativa terapéutica o de suplemento, frente a las faltas e insuficiencias en la constitución del sujeto. En algunos casos, en que las soluciones (neuróticas, psicóticas o perversas) "ordinarias" son insuficientes, el consumo de sustancias psicoactivas vendría a paliar esta insuficiencia. Para Escande (2002), la sustancia psicoactiva sirve como un moderador ideal para responder a la falla de la imagen de sí. El sujeto que se identifica con la denominación de drogadicto o toxicómano busca lograr una identidad imaginaria y una identificación que proviene del Otro. Por este acto de identificación con esta denominación que proviene de un Otro de lo social que le lanza al sujeto un discurso medicalizado y frecuentemente estigmatizante sobre los efectos del consumo compulsivo de drogas y sobre la identidad de aquel que es dominado por los efectos del consumo, el sujeto establece una forma de relación con el goce y un uso particular del cuerpo, en un esfuerzo por vencer la angustia. "El universo del toxicómano es la promesa de un paraíso donde el Otro es sustituido por un objeto de necesidad, un objeto inerte que no traiciona" (Escande, 2005, pp. 27 y 28). Para hacer una comparación con la neurosis, mientras el neurótico no para de perseguir un objeto plus de goce, algo que pueda menguar la dolorosa tarea de enfrentarse a la falta, la respuesta del drogadicto es más radical. Para este el objeto droga es considerado un producto partenaire - compañero, pareja - o causa última y sostén del ser del sujeto. Este lazo artificial ahorra o suaviza los avatares de las relaciones de objeto de la vida cotidiana y en relación con la alteridad (decepciones, inconsistencias, rupturas, pérdidas o desapariciones). Sin embargo, en la experiencia de todo aquel que se identifica con la denominación de drogadicto o toxicómano, la droga siempre decepciona a sus consumidores por la naturaleza misma del pharmakon bien conocida desde Platón (Derrida, 2006). Esta desilusión se revela en la erosión de sus efectos placenteros y en el retorno permanente de múltiples experiencias de pérdida vividas a lo largo de las experiencias de consumo que acarrean el desgaste del producto en el cuerpo y el desgaste del cuerpo. No obstante, incluso cuando la promesa de la droga se rompe sistemáticamente, la ilusión sobre su efectividad definitiva permanece; y aquellos que se ven encerrados en el acto compulsivo del consumo, se conforman con la ilusión de encontrar algún día la efectividad absoluta del producto, en la que alguna vez llegaron a creer. Para sostener esta ilusión están incluso dispuestos a sacrificarse en el exigente trabajo de búsqueda y experimentación de nuevos productos y de la dosis perfecta. Se trata de un camino que a menudo conduce a la combinación de diferentes tipos de fármacos (Rivera-Largacha \& de Neuter, 2008). 
El rechazo del drogadicto al discurso de la reinserción y su rechazo al cuerpo. Dentro del trabajo de campo que sustenta esta investigación, hemos tenido acceso a testimonios directos aportados por los usuarios de estos centros de atención y de los profesionales que laboran allí. En la revisión de estos testimonios, hemos encontrado que entre los usuarios la situación provocadora del abandono del cuerpo al que hemos hecho referencia revela la queja del sujeto de haber sido dejado de lado, despedido, botado, abandonado en uno o en varios momentos de su historia. Estas acusaciones dan cuenta de un rechazo (el del Otro) contra otro rechazo (el abandono del cuerpo propio).

En su punto extremo, el olvido del cuerpo revela, más que una ausencia de cuerpo, una paradoja: en el cuerpo afectado, el cuerpo real parece tomar un lugar protagónico una vez que el cuerpo psíquico se borra. Esta clínica del rechazo del cuerpo, que está generalmente acompañada por la falta de enunciación, por un desinterés o un rechazo evidente a hablar de sí, pone de relieve todas las dificultades o la imposibilidad de estos sujetos de inscribirse o de encontrar un lugar en el lazo social y, principalmente, en el discurso de la prevención o de la reinserción. Respecto a este discurso de la reinserción, es de anotar que Francia, desde hace más de veinte años, ha adoptado los modelos de atención basados en la lógica de la disminución de riesgos, principalmente a través de los agentes médicos, que han desplazado poco a poco las intervenciones policiales. En Colombia, los programas ofrecidos por el Estado están basados en un discurso que no logra desprenderse de una lógica de vigilancia y control y que tampoco logra desprenderse del discurso de lucha contra la producción de drogas dominante en este país, considerado uno de los principales productores de derivados de coca en el mundo.

Entre las personas entrevistadas en ambos países, la posición de rechazo al discurso de la reinserción tiene como función común proteger al sujeto del goce de un Otro potencialmente amenazante.
En el sistema de intervención propuesto por los hogares de paso, este rechazo encuentra un lugar en las mismas inconsistencias del sistema. Ya hemos descrito cómo, a pesar de ser constituidos oficialmente como espacios de reinserción, estos centros son asumidos por la mayoría de sus usuarios como lugares de protección contra el desgaste que impone la precariedad de las condiciones de vida en la calle. En el hogar de paso, los usuarios se pueden procurar una mínima recuperación física, que no está relacionada para la mayoría de ellos con un cambio de vida, ni con una transformación en sus hábitos de consumo.

En los Caarud, esta posición de rechazo al discurso de la reinserción origina diversas dificultades en el acompañamiento, por ejemplo cuando algunos usuarios, van a la deriva, no soportan ni la vida en squat (espacios ocupados a la fuerza por personas que carecen de una residencia formal), ni en alojamiento transitorio en habitaciones de alquiler. En estas situaciones, con regularidad, la preocupación que por ellos demuestran los miembros del equipo de atención se percibe como una especie de persecución. En aquellos casos donde se da una pérdida de un lazo que servía de piso (muerte de la pareja, entrada de la pareja en un proceso de reinserción, encarcelamiento) no es raro que algunos experimenten un verdadero naufragio subjetivo evidente por un exceso de consumo, empeoramiento del estado de salud y aumento de conductas de riesgo.

Otras situaciones en las cuales se evidencia la pérdida de los lazos son los fracasos de los usuarios de los Caarud cuando deciden emprender un proceso de rehabilitación acudiendo a tratamientos dentro de estructuras especializadas de salud (hospital, centro médico, etc.). En muchos casos, las frustraciones que derivan de estos episodios enmarcan el inicio de un retroceso o una desconexión del usuario respecto al equipo de profesionales. Todos los escenarios son imaginables e imaginados por el equipo: suicidio, muerte accidental, sobredosis, errancia, cambio de ciudad, fuga por asuntos penales, encarcelamiento u hospitalización psiquiátrica. 
En el caso de los usuarios de los Caarud tratados por hepatitis $\mathrm{C}$, la ausencia de un referente (que pueda servir como punto de anclaje), el aumento de las exigencias dentro de los tratamientos, las demoras dentro de estos, sus restricciones y consecuencias en el plano somático pueden empujar al usuario a salir del discurso, quienes prefieren el riesgo fatal (la muerte) para escapar cueste lo que cueste a la confrontación con la frustración - (castración) para quienes están del lado de la neurosis - o de la sobrepresencia del Otro del goce - entre quienes se encuentran del lado de la psicosis - El rechazo de los cuidados y los tratamientos médicos entre los drogadictos en situación de abandono social sugiere que toda mejoría de su estado sería insoportable. En estos casos, el protocolo de tratamiento fracasa y luego se da una recaída, un agravamiento de los síntomas, como una forma de "reacción terapéutica negativa" (Freud, 1923).

Este obstáculo, que se opone a la cura, en la neurosis está clásicamente ligado a la culpa, acompañada de la satisfacción que el sujeto encuentra en el mantenimiento y persistencia de su enfermedad. El sujeto halla en el sufrimiento o en el dolor una satisfacción por el castigo. Esta posición, fundamentalmente transgresora, se puede entender como un intento por conservar un control defectuoso de la situación donde el sujeto es quien produce el fracaso, el rechazo en vez de soportar la repetición de una nueva experiencia de abandono. Esto se relaciona con el concepto de autopunición, desarrollado por Hesnard y Laforgue, con el que han ampliado el campo fuera de la neurosis, para mostrar su rol tanto en las psicosis como en el curso de algunas afecciones de sintomatología orgánica. Estos autores señalan esta posición sadomasoquista como una posición que permanece velada en el individuo (Hesnard \& Laforgue, 1931, pp. 4-9). Los autores evocan el trabajo de Alexander en un cierto número de individuos llamados nerviosos, más o menos desequilibrados, que viven "al margen de las leyes o de códigos de honor", quienes se comportan como "enemigos de la sociedad o como perversos" o aún como "originales" o "excéntricos". Esto con el objetivo, subjetivamente desconocido pero objetivamente manifiesto, de hacerse señalar como culpables o de hacerse rechazar por las personas cercanas, hacerse sancionar profesionalmente o, incluso, hacerse condenar penalmente y situarse como víctimas frente a los otros. Se trata de una posición autopunitiva de parte del sujeto. Estamos entonces en las fronteras con la psicopatía y las conductas llamadas desviadas. En la psicosis, la autopunición es generalmente más intensa, puesto que se origina en la violencia de un superyó arcaico y representa un amplio espectro: la melancolía y su autoacusación masiva, la manía y sus pulsiones sádicas o los procesos de incursión en la esquizofrenia con disminución progresiva y selectiva de la vida afectiva, como un repliegue autista hasta la autodestrucción. Con respecto al tema de la autopunición en la psicosis, Hesnard y Laforgue afirman:

La aspiración inconsciente de la muerte excedería así puramente el plano psíquico y se cumpliría realmente, $[\ldots]$ hundiéndose en la intimidad estructural, $[. .$.$] y yendo del sado-masoquismo silencioso$ hacia la autodestrucción material y hacia la muerte, orgánica o total del ser (1931, p. 52).

La deficiencia de lo simbólico conduce a muchos sujetos a tratar de sostenerse exclusivamente en la dimensión imaginaria. Algunos sujetos intentan inscribirse en un funcionamiento "como si", síndrome elucidado por Helene Deutsch (2007) en los años cuarenta, cuando estudiaba las particularidades de la esquizofrenia y describió a estos sujetos como influenciables, sin dirección propia, e identificó los antecedentes de esta condición en la existencia elementos específicos del ambiente familiar o de los hábitos o ideales del medio que rodea al sujeto. Para Deutsch, la esencia de la esquizofrenia está en la imagen tomada del otro. Esta adhesión extrema por imitación puede llegar hasta la mitomanía. La base generalmente frágil cede 
ante las vicisitudes de la vida (muerte, despido, separación, etc.), donde la persona se encuentra excluida del grupo o de un modo de convivencia y así es brutalmente precipitada en los tormentos de la angustia, de la errancia que el uso de productos intenta amortiguar.

Drogadicción y errancia pueden conjugarse en situaciones donde se impone la desprotección y un desapego con respecto al propio cuerpo, que se acentúa con el consumo repetitivo de drogas. La droga puede servir como anestésico para el dolor y hace casi imposible el trabajo de elaboración psíquica. El sujeto no siente nada, no espera nada, no pide nada (alojamiento, ayuda, etc.) absorbido por la experiencia sensorial rítmica de la incorporación de droga y por el posterior desgaste de sus efectos. Se trata de una suspensión del tiempo y una búsqueda de la inmediatez coherente con un intento por encontrar un modo de goce que viene a reforzar la división con el Otro. En estos casos, se observa una trayectoria que está muy lejos de la versión de compromiso que representa el síntoma (Sauret, 2008). ${ }^{7}$

El rechazo del tratamiento o de las ofertas de reinserción no son una forma de dimisión o borramiento de sí; muestran una sospecha frente al discurso del Otro y a la función paterna. Paradójicamente, en estas condiciones el cuerpo se convierte en una envoltura incómoda y un objeto de desecho sometido a la negligencia. Muchas veces el perro de compañía goza de un mejor trato que el propio cuerpo.

Esta negligencia del cuerpo es una forma de desligarse de un objeto que es la materialización del Otro, siendo este último una figura que es

7 Dentro del modelo lacaniano, el síntoma, la manifestación particular del sujeto, que pone en evidencia lo que le es más propio. Se trata de la manera particular como cada sujeto - en el caso de la neurosis - hace frente al sentimiento de incompletud que marca en él los efectos de la castración, que hacen evidente en el sujeto su falta. Por medio del síntoma, el sujeto hace frente a la falta, aunque sea de manera precaria, por medio del sacrificio de una parte importante de su tendencia a la satisfacción inmediata. insoportable para el sujeto esquizofrénico. Si para el neurótico el cuerpo puede ser un partenaire, un compañero, un interlocutor, un espacio de inscripción de acontecimientos, en el esquizofrénico este mismo territorio es la posesión de un Otro primitivo, de cuyo dominio busca deshacerse.

Como fenómeno transestructural, el proceso de autopunición puede situarse en el origen del rechazo al tratamiento y a la reinserción. Rechazo que puede también ser acentuado por la intervención "humanitaria" del Otro de lo social. Es el caso de una usuaria de un Caarud, quien al buscar recuperar a su hija y restaurar su dignidad de madre, va a comenzar un proceso de desintoxicación de alcohol, acompañada y sostenida por un miembro de un grupo religioso. Pero este exceso de "caridad cristiana" encarna para ella una presencia excesiva y una violencia superyoica del Otro, que la va a hacer precipitarse en el consumo de drogas y el exceso de consumo de alcohol. Frente a los fantasmas de la reinserción rápida y de la desintoxicación exitosa, se da una deconstrucción defensiva que lleva a muchos sujetos a repetir los fracasos. Este funcionamiento de resistencia y de objeción ante el furor sanandi, contra el que Freud habría ya advertido, puede dar lugar a diferentes signos clínicos: desde la pérdida repetida de documentos de identidad, que coloca al sujeto fuera de toda posibilidad de acción referente a los procesos de búsqueda de ayuda, hasta situaciones extremas de pasaje al acto suicida o sobredosis. Una viñeta clínica de Declerck (2001) puede ejemplificar nuestras afirmaciones. Un residente de "quien los trabajadores sociales, los psicólogos esperan un futuro radiante" (p. 89) es acogido en el centro de reinserción durante seis meses. Al mes y medio de estar en un programa de estadía exterior (que sería el último paso en su proceso de reinserción) vuelve a beber y desaparece antes de morir frente al Hospital de Nanterre.

Enceguecidos por alguna "pasión por el bien", los profesionales pueden olvidar la doble función que tiene el consumo de drogas. Por una parte, este 
recurso corresponde a una búsqueda de automedicación de algunos síntomas principalmente en fases agudas (angustias disociativas, sentimientos de transformación corporal, ambivalencia afectiva, etc.). En otras situaciones, el consumo permite, por los efectos de confusión de la realidad, justificar o intentar controlar las representaciones o una sensorialidad delirante, como una vivencia de extrañeza inicial.

Frente a la ausencia o al fracaso de la castración simbólica, el consumo de drogas vendría así a asegurar una continuidad del ser, crear una unidad imaginaria y transitoria del cuerpo que calma la angustia y atempera un goce localizado en el Otro (por no estar sometida a la norma fálica). Así, el consumo de sustancias permite (principalmente en la psicosis) un cierto funcionamiento masivo del goce ante la ausencia de un fantasma fundamental. De allí el horror al cual se enfrentan ciertos sujetos frente a cualquier interrupción brutal del consumo. A pesar de que el consumo para el drogadicto es una cadena de comportamientos tediosa y llena de sufrimientos, el abandono de esta tendencia masoquista puede ser aún más doloroso y puede significar una destrucción definitiva para el sujeto. El tratamiento subjetivo que se construye en el consumo compulsivo de drogas se entiende entonces como la última tentativa para escapar a la objetivación del discurso social, educativo o médico.

\section{Funcionamiento masoquista de la drogadicción y las lógicas de uso indebido de los tratamientos de sustitución}

Antes de avanzar en nuestra reflexión es necesario hacer una aclaración importante sobre el tema de los tratamientos de sustitución. Estos se ofrecen a personas adictas a los opiáceos (principalmente los usuarios de heroína) basados en el uso de una sustancia similar en su composición química a la normalmente consumida por la persona afectada. Estos tratamientos se presentan dentro de una oferta de intervención psicofarmacológica como instrumentos adecuados para disminuir los efectos del síndrome de abstinencia y, por esta vía, limitar los riesgos y daños a la salud o los riesgos sociales asociados al consumo de drogas químicas.

En Colombia, el establecimiento de estos tratamientos no es tan importante, ya que el consumo de heroína no tiene una alta prevalencia y no existen aún tratamientos de sustitución para los consumidores de derivados de la coca, que son en cambio las drogas de mayor uso entre la población de habitantes de calle, en especial el bazuco. Particularmente por su alto costo, los opiáceos son usados muy raramente entre las poblaciones más vulnerables y de menores recursos. Sin embargo, asistimos a un aumento en el consumo de opiáceos en Colombia (Camacho et al., 2010) que probablemente abrirá la puerta en el futuro al debate sobre la posible introducción de tratamientos de sustitución dentro de las ofertas de intervención en salud para este tipo de población. Por otro lado, aunque todavía no existen drogas de sustitución probadas para los consumidores de derivados de la coca, es posible que este tipo de medicamentos aparezcan pronto como resultado de las investigaciones farmacológicas, y para su implementación es indispensable revisar las experiencias obtenidas en el caso de las drogas de sustitución paliativas para consumidores de opiáceos.

Si el uso de sustancias psicoactivas hace lazo, es mediante las relaciones tejidas bajo la forma de identificación con los semejantes. La vida de los usuarios (consumidores) se organiza alrededor de las drogas o de la forma de conseguirla. Así, los otros, los semejantes, quedan reducidos a meros instrumentos para lograr el objetivo de la búsqueda o a simples acompañantes en esta carrera. En este sentido, el recurso a las drogas se inscribe en la ruptura con las exigencias del Otro. Conforme avanza el consumo y la instalación en la dependencia, el lazo social se descompone y frecuentemente la familia es la primera distanciada. 
La pregunta que tienen que enfrentar los profesionales que se dedican al acompañamiento de personas que presentan un consumo problemático de sustancias es: ¿cómo hacer sin el Otro, cuando el usuario se inscribe en el programa de rehabilitación? Esta pregunta se hace aún más problemática cuando el lugar ofrece un tratamiento de sustitución. La prevención de los riesgos, que es la base conceptual del tipo de atención de los lugares de acogida de baja exigencia en Francia, es generalmente un discurso privilegiado para la apertura de nuevas formas de significación de la vida propia para los usuarios de drogas que se encuentran en situaciones de extrema precariedad. Sin embargo, muchas veces estos lugares pueden ser también el escenario de repetición de la alienación. El lugar que ocupan allí los médicos es problemático, ya que algunos frecuentemente se sitúan en el lugar de "dealers con bata blanca". Históricamente, las políticas de sustitución tienen como efecto la entrada en la escena del médico dentro de un espacio en el que todas las personas que presentaran consumos problemáticos de drogas parecían impermeables a cualquier tratamiento farmacológico. En 1993, al introducirse la política de la sustitución en Francia como mecanismo de atención a las personas afectadas por el consumo problemático de drogas, se redacta una primera circular que propone: "diversificar las modalidades de apoyo, incluyendo el uso de la prescripción de Metadona ${ }^{\mathbb{B}}$ ", prescripción iniciada por estructuras de hospital o centros especializados, con el fin de facilitar el acceso a usuarios de sustitución que quedaban fuera de la cobertura de las redes de atención especializada. La circular del 30 de marzo de 1995 introduce otra molécula comercializada bajo el nombre de Subutex ${ }^{\circledR}$, que pueden prescribir los médicos generalistas. La implementación de estos programas ha ayudado a reducir a la mitad el riesgo de transmisión del VIH relacionado con la inyección intravenosa y tomado por vía nasal y a la vez ha generado una transformación radical en la manera como socialmente se representan las drogas y los consumidores de estas sustancias.

Luego de años de estigmatización de las sustancias y sus consumidores, la doble faceta del pharmakon vuelve a la escena: se da una mutación dentro de las representaciones sociales e individuales que se tejen entre los usuarios de drogas, el personal médico y el público general respecto a esta herramienta terapéutica que pone a disposición de los consumidores una droga.

Estas transformaciones en las representaciones sociales de las drogas ilegales, de la figura del toxicómano y de las drogas de sustitución, las ha analizado Gomart (2004) desde el punto de vista de los estudios sociales de las ciencias, quien dentro de un trabajo de campo elaborado a través de una metodología innovadora devela las tensiones de poder que se tejen dentro de una clínica de atención a drogadictos en Francia. En su artículo se evidencia cómo la definición y el lugar simbólico que se le otorga a la molécula de la droga de sustitución acompañan una transformación en la manera como el toxicómano se define y se trata dentro de la red que vincula a los equipos médicos, psicosociales y a los actores políticos.

Las conclusiones de este trabajo muestran cómo las drogas de sustitución abren el campo de comprensión respecto a la condición del drogadicto y, de esta forma, adaptan los mecanismos de intervención para estas personas entendiendo su condición como resultado de una variedad de factores médicos y psicosociales. Los resultados, además, muestran que los remanentes históricos de la atención médico-policiaca que durante mucho tiempo marcaron las directrices de la atención a estas personas siguen estando presentes en la forma como se establecen y se manejan los tratamientos de sustitución y en la manera como es situado el consumidor de drogas dentro de esta red.

En nuestro trabajo de campo hemos observado que en estas circunstancias en las cuales se propone una sustancia legal como herramienta de 
tratamiento contra la adicción a una sustancia ilegal, los médicos pueden encarnar, incluso a pesar de sí mismos, una figura confusa entre prescriptor y el dealer. Con sus propuestas y peticiones, el médico prescriptor puede hacer obstáculo o ruptura con la parte autista del síntoma, es decir, aquella que se resiste a dar cualquier significación al malestar de la persona y se opone a cualquier tipo de alteridad y de distancia respecto a la droga. De ubicarse el médico del lado del dealer (que es frecuentemente la posición que muchos usuarios le exigen ocupar), se aliaría con esta parte autista del síntoma. La gran dificultad es que dentro de la relación entre el paciente y el médico los límites de diferenciación entre el prescriptor y el dealer tienden a ser frágiles y confusos, y esto a pesar de los esfuerzos que haga el médico por sostener por ejemplo su posición de prescriptor. Esto obedece a un hecho contundente $\mathrm{y}$ es que el consumidor llega a los tratamientos de sustitución como último recurso, luego de una trayectoria en la que él ha sido su único prescriptor y ha logrado evadir cualquier cuestionamiento de la parte de un otro respecto al goce de su cuerpo.

Dentro de las propuestas de tratamiento de los centros especializados en Francia, el usuario puede elegir entre diferentes protocolos de atención de acuerdo con sus necesidades. El protocolo de bajo umbral (bas seuil) corresponde únicamente a la distribución de Metadona ${ }^{\circledR}$ por parte de centros especializados; mientras que el protocolo de alto umbral (haut seuil) implica para el usuario, además, un apoyo multidisciplinario que incluye un apoyo educativo, psicológico o social. La distribución de Subutex ${ }^{\circledR}$ es menos controlada, puesto que puede ser recetado por médicos generalistas como primera opción de tratamiento. El protocolo de 28 días de Subute ${ }^{\circledR}$ evita al usuario las dificultades de trasladarse diariamente a un centro de atención y permite eliminar el apoyo multidisciplinario.

La manera en que el usuario respeta o no las prescripciones pone en evidencia su posición subjetiva. El mal uso de las drogas de sustitución no responde a la misma lógica en cada usuario. Con la puesta en marcha de tratamientos de sustitución, los usuarios de heroína u otros opiáceos se encuentran en un rango de sujetos tóxico-dependientes. Se trata de un grupo de pacientes entre muchos otros, es decir, son personas sometidas a lo que llaman Gori y Del Volgo (2005) la medicalización generalizada de la existencia. Sin embargo, sobre ellos subsiste una estigmatización desde la cual están desempoderados, culpabilizados o identificados socialmente con la función de desechos. Las consecuencias de la entrada en un programa de sustitución son significativas, y la cotidianidad del Caarud constantemente da cuenta de las consecuencias e impasses subjetivos que surgen. Por un lado, porque el Otro impone al usuario un modo de ser, una utopía que reposa sobre la desaparición del síndrome de abstinencia y una ideología de un "buen uso" del medicamento; por otro, porque la práctica pasa de la ilegalidad a la legalidad, pasa de un multiconsumo experimental a un monoconsumo medicalizado. Al perder el producto su carácter transgresivo, pierde su mayor atractivo: la capacidad de dirigirse hacia lo que Lacan llama el goce del Uno. De acuerdo con este planteamiento, la Une-jouissance (goce-Uno) es el goce que pertenece al campo de lo Real. Esta forma de goce antecede - dentro de la historia psíquica del sujeto- al goce fálico o goce sexual, que resulta de los efectos de la castración en la forma en la que el humano goza. Los efectos de dicha castración introducen al sujeto y a su goce dentro del orden simbólico. Así, el goce-Uno corresponde a un goce primitivo, arrebatador para el sujeto, puesto que no está atravesado por el orden simbólico (Rivera-Largacha \& de Neuter, 2008).

La entrada en un protocolo de tratamiento puede verse (fuera de los efectos aparentemente apaciguadores psicológicos y físicos) como insoportable, dada la doble dependencia que induce el tratamiento de sustitución. Ya no solo se es dependiente de la droga, sino que, además, el sujeto depende de un sistema social que le impone unas exigencias de comportamiento. Es una situación para muchos insoportable, puesto que justamente su adherencia 
a las drogas era una forma de resistirse a cualquier exigencia social. Desde esta óptica, se pueden enmarcar dos posiciones subjetivas: la primera consiste en provocar al Otro médico en una escenificación del sufrimiento. Encontramos aquí el tono demostrativo de todo acting out. Así, la señora B que estaba insertada en lo social, pierde esto a causa de su alienación a la heroína, su apartamento y su empleo. Consumidora de heroína desde hace seis años por vía nasal, después intravenosa, tras (según ella) un evento traumático (accidente grave de tránsito y rehabilitación severa de muchos meses), tuvo que interrumpir las inyecciones por problemas severos de abscesos. Conoció el Subutex ${ }^{\circledR}$ en el mercado negro y remarca el carácter benéfico del producto, puesto que suprime el dolor ligado a la abstinencia. Una vez esta mujer entra en el protocolo de sustitución, regresa a vivir en la casa de su madre, quien le resta responsabilidad, al considerar a su hija como una enferma: "tengo 30 años, pero mi mamá todavía hurga entre mis cosas". La señora B se ve obligada a pasar a la Metadona ${ }^{\circledR}$ luego de un mal uso de Subutex ${ }^{\circledR}$ tras haber "confesado" sobre este mal uso y haberse puesto en evidencia frente al médico que la trataba. En efecto, el consumo de Subutex ${ }^{\circledR}$ por vía nasal le permite tener control sobre el objeto droga, no sentir el sabor desagradable y perpetuar una conducta similar a la que tenía inicialmente con la heroína: se trata, pues, de un control sobre el goce. La entrada del médico como figura paterna, detentor de un saber y de un poder sobre la posología, sitúa a la señora $B$ en una posición pasiva y sumisa. A pesar de las prácticas de mal uso (de las que ella puede dar testimonio posterior al tratamiento) estas permiten al sujeto atacar la posición del sistema médico de "pequeño maestro" y reivindicar a través del acting out su singularidad: "eso me pasó... No lograba levantarme para venir, mi compañero tomaba Subutex ${ }^{\circledR}$ entonces de una yo tomé Subutex ${ }^{\circledR}$, lo que jamás debí haber hecho porque uno siente más la sensación de abstinencia, lo que es aún peor. Hubiera sido mejor no tomar nada de nada y yo lo tomé, yo lo tomé debajo de la lengua”. Solo el malestar y el dolor del cuerpo producidos por el uso indebido del Subutex ${ }^{\circledR}$ llegan a poner un límite al goce: “es aún peor - afirma la señora B-, luego es mejor no tomar nada".

El mal uso del tratamiento en el caso de la señora $\mathrm{B}$ es una objeción, que viene dada por manifestaciones inconscientes dirigidas hacia el Otro y significa la emergencia del sujeto. Posteriormente, la dinámica de satisfacción/insatisfacción que introduce, el tratamiento de sustitución de Metadona ${ }^{\circledR}$, parece restaurar la dimensión deseante: "Se tienen ganas de hacer más cosas, se tienen ganas de volver a trabajar, eso es positivo al menos". El balance que hace esta persona al revisar su historia es, sin embargo, precario y dentro de su relato se cuestiona profundamente por su autonomía: "ya con mi compañero, queremos tener nuestro camión e irnos". El riesgo para la señora B, al buscar emanciparse de nuevo de las figuras parentales (la madre o el médico), son las inevitables recaídas. Así, al no poder poner en evidencia e interpretar el sentido de las conductas de uso indebido del lado de una manifestación inconsciente del sujeto, la respuesta médica se resume frecuentemente a un cambio de drogas que reactiva de facto el ciclo de coconsumo de drogas ilegales o de usos desviados de medicamentos $\left(\right.$ Stilnox $^{\circledR}$, Valium $^{\circledR}$, Néocodion $^{\circledR}$, etc.), o incluso de recaídas sin fondo.

En otros casos, el uso incorrecto de drogas de sustitución se inscribe en la continuidad de la búsqueda de goce del Uno. Todo cambio de droga (como el cambio del Subutex ${ }^{\circledR}$ a la Metadona ${ }^{\circledR}$ ) solo tiene un efecto menor, el sujeto encontrando otros modos de evitar la ley dictada por el Otro, de rehusarse a la castración con el fin de seguir siendo el dueño de su goce. Así, el señor F, que consumió Subutex ${ }^{\circledR}$ en la prisión por vía nasal para "hacer lo mismo" que otro prisionero. Finalmente, interrumpe esta forma de consumo a la salida de la prisión bajo la orden de un médico que se erige en la posición del Otro parental, entonces sitúa la prohibición y le pone límites al goce. El señor F 
deriva de la prohibición impuesta un goce asociado al Subutex ${ }^{\circledR}$, que cotidianamente va a buscar: "Cada mañana espero conseguir mi buprenorfrina; es una pequeña alegría para mí". Para este hombre el modo de consumo es accesorio; es el efecto del producto lo que es buscado. Este que viene a llenar una hiancia narcisista: "necesito sentir lo que está en mí, que eso me penetró a mí”. Respecto a los consumos vía nasal, $\mathrm{F}$ reporta principalmente los efectos estimulantes de la droga. Por vía oral, una sensación de placer anterior al efecto farmacológico referido a la excitación de las mucosas de la boca: "El hecho de sentirla bajar; como se deshace casi... Yo encuentro eso agradable”. El mal uso persiste, del lado de un uso excesivo de la droga, los fines de semana y de una alcoholización rápida y compulsiva cada atardecer, momento que él califica de "punto casi muerto".

Jacques (1997) recuerda la introducción de una "ley biológica" de la dependencia, que toma la delantera sobre el cuerpo, contrariamente a la ley penal, que sanciona únicamente cuando el individuo es atrapado. Sin embargo, cuando el usuario entra en un programa de sustitución institucionalizado, se ve privado de la ley que impone la abstinencia, puesto que la droga le es dada cotidianamente. Para encontrar de nuevo la angustia de la sensación de abstinencia, desvía la prescripción inicial. Dentro del sistema de prescripción de drogas de sustitución, la gran dificultad del médico consiste en que dentro de la relación con estas personas que demandan de ellos una solución a sus problemas aparentes no logra identificar la resistencia que simultáneamente hacen frente a la posibilidad de curarse de su adicción. Muchos médicos se sitúan de parte de la formulación de una droga para satisfacer la necesidad evidente y manifiesta de sus pacientes, sin dejar lugar a la palabra del sujeto, de manera que este último se encuentra borrado detrás de la utopía del proyecto de cura a través del medicamento.

Ir más allá de la prescripción sistemática de productos farmacéuticos, preguntarse sobre aquello que está más allá de la demanda del usuario, permitiría en cambio articular dicha demanda a una problemática subjetiva singular. Cuando el usuario reivindica su problemática a través del "mal uso" del que es testigo un médico, un proceso de subjetivación puede estar constituyéndose y permitir una desalienación progresiva del sujeto con respecto al producto $y$, por lo tanto, un compromiso particular en el tratamiento.

Sería interesante, dentro de esta lógica, considerar las numerosas vueltas al consumo no como recaídas (fracasos), sino como maneras de actuar frente al Otro. En el caso de Colombia, donde los tratamientos de sustitución no están incorporados dentro de una política de intervención frente a las poblaciones de consumidores de drogas, las experiencias de Francia y de otros países pueden ser un ejemplo para mostrar la necesidad de tener en cuenta la posición de confrontación permanente para el drogadicto cuando se trata de cambiar su posición frente al sistema de vigilancia médica que está ligada a este tipo de tratamientos. De igual forma, dentro de la propuesta de acompañamiento psicosocial que funciona actualmente y que no provee productos de sustitución, pero que ofrece bienes y servicios, el mal uso o el abandono del programa de reinserción se convierten en fracasos en la medida en que el equipo que acompaña este tipo de intervenciones y el sistema de atención en general no es capaz de entender la particularidad del sujeto y su manera personal de hacer un llamado al Otro.

\section{Conclusión}

En las propuestas del psicoanálisis contemporáneo se plantea que la entrada al mercado de cualquier bien o servicio va de la mano de una ilusión de un acceso ilimitado a lo que Lacan llamó el goce. Este paso de una sociedad articulada alrededor del goce fálico (caracterizado por un acceso a la satisfacción, limitado por un acuerdo social que exige al sujeto la renuncia al acceso inmediato e ilimitado 
a los objetos que le proporcionan dicha satisfacción) a una sociedad donde prima el goce objetal (en la que la satisfacción no está limitada por un pacto social) produce una nueva economía psíquica (Melman, 2002; Melman \& Lebrun, 2009).

El término recusación, introducido por Czermak (1998) para ilustrar lo que está en juego en las amnesias de identidad, parece funcionar también para esclarecer las problemáticas de los drogadictos. En efecto, esta noción de recusación del nombre del padre (de aquello que dentro de los acuerdos culturales establece normas de convivencia comunes) es diferente de la noción de forclusión (anulación completa) y de negación, que dentro del esquema lacaniano explica el origen de las psicosis. El término de la recusación designa el modo por el cual algunos sujetos se deshacen de su inscripción, en cuanto sujetos deseantes, y siguen, en este sentido, el mandato de un mundo que promociona la posibilidad de obtener en cualquier momento una satisfacción inmediata. La deuda de la vida no es pagada por medio de la castración simbólica, sino por una deuda del cuerpo, una restricción en el cuerpo que ocupa un lugar central tanto en la intoxicación como en los estigmas que marcan el cuerpo o en la experiencia dolorosa de falta psíquica que acompañan esta experiencia (Escande, 2002). Comúnmente, este tratamiento del cuerpo mediado por el consumo de drogas, lejos de hacer desaparecer los problemas propios y de dar una unidad al cuerpo, muestra de manera radical que este es una "una pila de piezas separadas" (Miller, 2004).

Si el psicoanálisis tiene como objetivo resolver el goce doloroso vía el sentido (apuesta por el uso de los recursos simbólicos), los sujetos llamados drogadictos prefieren hacer frente a este goce doloroso usando el cuerpo desde una posición masoquista y evadir toda posibilidad de sentido de interpretación o de uso de la palabra para dar algo de límites a las contingencias de su propio cuerpo. Estos sujetos no logran acceder a referentes simbólicos que les permita reconstituir una mínima unidad dentro de su cuerpo.

Esta desarticulación corporal obstaculiza, además, cualquier tentativa de estructuración de un mínimo lazo social, pues no se cuenta siquiera con una certeza de sí que haga posible un contacto con otro, sin que el sujeto lo perciba como una invasión amenazante. De ahí el riesgo de depreciación social - si nos permitimos acá tomar prestada la expresión de la sociología de Caradec (2004) — cuando el síntoma no puede ser resaltado para permitir anudar lo más particular del sujeto al lazo social. Frente a la dirección generalmente persecutoria a la que puede conducir el acompañamiento de algunos usuarios dentro de las instituciones que trabajan con personas dependientes de las drogas, a veces se puede ver una circulación - ya no de la droga, sino del individuo - de lugar en lugar. En Francia, esta circulación se da de institución en institución: Caarud, medicina liberal, servicio hospitalario del día, urgencias, etc. Dicha circulación tiene como causa la imposición de las sanciones frente al rompimiento de las reglas propias de la institución o del acompañamiento, lo cual desemboca en la exclusión. En Colombia, la escasez de este tipo de recursos médico-psicosociales delinea otro tipo de recorridos: hogar de paso, calle, cárcel, urgencias, etc. Si dentro de los dos contextos se plantea otra modalidad de intervención, si se piensa verdaderamente y se orienta el trabajo por el interés de dar lugar a la particularidad de cada sujeto y no se concibe simplemente como un medio de normalizar los comportamientos desviados, es posible encontrar una alternativa a los problemas de deserción y de falta de adherencia a las propuestas de tratamiento médico-psicosocial para este tipo de población. Una intervención de tal naturaleza debería tener como base un trabajo colectivo que logre el objetivo de mantener una verdadera continuidad en el acompañamiento clínico entre los profesionales y entre las instituciones. Una organización de este tipo es importante cuando las personas no solicitan 
ya ninguna ayuda (lo que es frecuente en el caso de las drogadicciones graves) y cuando:

La alianza del sujeto con el significante es fragilizada por el pacto de hierro establecido entre el sujeto y el goce mortífero [...], es decir en los casos en que el goce supera y neutraliza al sujeto en su capacidad de acudir a lo simbólico para salvarlo de la pulsión de muerte. (Di Ciaccia, 2005, pp. 107-118)

Sin ceder a las alertas normativas y segregadoras que históricamente han sido la norma dentro de un contexto de prohibición del consumo que estigmatiza al consumidor, el intentar una organización de trabajo grupal entre los actores del campo social que permita un funcionamiento en red tiene como objetivo crear un soporte enunciativo que evite a los profesionales sentirse depositarios de un saber exclusivo sobre los usuarios. En efecto, dentro del trabajo que implica la cruda realidad de aquellos que lo han perdido casi todo por su relación con las drogas, la fascinación inducida y la captación de miradas, toda la exhibición del goce puede resultar enceguecedora para quienes intentan ofrecer ayuda a los drogadictos.

Al no centrarse en los signos llamativos que el uso de sustancias psicoactivas y una larga trayectoria en la calle revelan, es posible diferenciar cada conducta y sintomatología, tanto en la forma en la que el sujeto la usa como en el equilibrio que le permite. Compartir y transmitir situaciones del contexto problematizándolas y analizándolas permite discernir la forma en que la acogida y el trabajo con estas personas puede sostenerse y dirigirse hacia el trabajo sobre: el cuerpo, el Otro pareja, el Otro social o la ley, etc., más allá del consumo de sustancias. Esta articulación de un lenguaje hecho en colectivo genera también un afecto compartido por los profesionales (violencia, agresividad, angustia, etc.) y tiene como virtud reintroducir al usuario en una alteridad del uso de la palabra, del lenguaje, subjetivando la situación crítica por medio de un esfuerzo de aprehensión y de extracción de un po- sible sentido, de una significación individual. Si se admite que el inconsciente (como discurso del Otro) es transindividual, esta operación de pensamiento en común busca redefinir las modalidades de acogida, como un eventual acompañamiento que podría dar como resultado una posibilidad de avance en un proceso de reinserción que no sea percibido como amenazante por el sujeto. Se trata de permitir al sujeto drogadicto retomar el hilo de su vida a partir de su síntoma, para reanudar lo real, lo simbólico y lo imaginario. Por eso el recorrido del drogadicto debe ser entendido cuidadosamente. El clínico debe recibir sus preguntas, sus intentos para alejarse de la droga, sus fallas, sus dificultades para soportar la falta como etapas en la indagación, algunas veces compulsiva y errática, sobre el lugar que ocupa en la articulación entre lo simbólico, lo imaginario y lo real, y por otra parte en la transformación de su relación con el Otro de lo social (Rivera-Largacha \& Gaspard, 2010).

En vez de denigrar al drogadicto y de querer resistirse a su empeño por la autosatisfacción por la vía de la droga, es posible apostar al reconocimiento del síntoma. Dentro de las propuestas del psicoanálisis, esto significa apostarle a la particularidad del sujeto y a su desestigmatización y de sus comportamientos. Se trata de reconocer un mínimo sentido dentro del caos de los comportamientos repetitivos, reconocer el síntoma para salirse de la lógica simplista del monosíntoma, admitir la imperiosa necesidad en la que se encuentra el usuario para hacer de la droga un recurso.

En resumen, el trabajo con personas drogadictas exige reconocer en cada una de ellas el estatus de sujeto y tomar en serio lo que nos enseña la clínica: con cada usuario se impone una ética. Solo una práctica del pensamiento en común que tiene lugar dentro de reuniones de equipo o de supervisión puede generar dentro del personal un indispensable esfuerzo de restablecimiento de los lazos que haga ruptura o que ponga un límite a aquello que, en una gran mayoría de los casos, no es más que repetición de un goce mortífero, degradación narcisista, re- 
ducción masoquista del ser a la condición de desecho; en conclusión, la obra de la pulsión de muerte.

\section{Agradecimientos}

A Martine Lacoste, directora general de la Asociación Regional Clémence Isaure, Toulouse, Francia (www.clemence-isaure.org), y a su jefe de servicio: Etienne Normand, director del Caarud, y todo su equipo. En Bogotá, Colombia, a la Secretaría Distrital de Integración Social de Bogotá, en especial a Mauricio Rodríguez, funcionario de esta entidad. Agradecemos también a Armando Steven Prieto, joven investigador de nuestro equipo, por su colaboración dentro de la traducción al español y una revisión previa del presente artículo.

\section{Referencias}

Alcaldía Mayor de Bogotá/Pontificia Universidad Javeriana. (2003). Inclusión social y nuevas ciudadanías: condiciones para la convivencia y seguridad democrática. Bogotá: Pontificia Universidad Javeriana, Facultad de Ciencias Políticas y Relaciones Internacionales.

Askofare, S. \& Sauret, M-J. (1998). La toxicomanie: perspective psychanalytique, sexualité et discours. Filigrane, 7(1), 66-80.

Aucremanne, J.-L. (1990). Le mariage avec la drogue. Quarto, 42, 62-66.

Babin, P. (2004). SDF, L'obscénité du malheur. Ramonville Saint-Agne: Erès.

Bergeret, J. (1982). Toxicomanie et personnalité. Paris: PUF.

Camacho, A. et al. (2010). El consumo de droga en Colombia. Bogotá: Ediciones Uniandes.

Cámara de Comercio de Bogotá (1997). Habitantes de calle: un estudio sobre la calle del Cartucho en Santafé de Bogotá. Bogotá: Cámara de Comercio de Bogotá.

Caradec, V. (2004). (Dé) prise, (dés) intérêt et étrangeté au monde. Vieillir après la retraite : Approche sociologique du vieillissement. Paris: PUF.
Chauvin, P., Parizot, I., Menahem, G., Guiguet, M., Pech, N. \& Lebas, J. (1999). Précarité, trajectoires de précarité, états de santé et accès aux soins: Rapport final de l'Inter commission $n^{\circ} 6$ de L'INSERM. Paris: Institut de l'Humanitaire.

Czermak, M. (1998). Amnésies d'identité ou de la récusation du Nom-du-Père. Patronymies. Paris: Masson.

Damon, J. (2012). La question SDF, Critique d'une action publique. Paris: PUF.

Declerck, P. (2001). Les Naufragés: avec les clochards de Paris. Paris: Plon.

Declerck, P. (2005). Le sang nouveau est arrivé. $L$ 'horreur SDF. Paris: Gallimard.

Derrida, J. (2006). La pharmacie de Platon. Paris: Flammarion.

Deutsch, H. (2007). Les comme si et autres textes: 1933-1970. Paris: Le Seuil.

Di Ciaccia, A. (2005). La pratique à plusieurs. $L a$ Cause freudienne, 61, 107-118.

Douville, O. (2004). Exclusions et corps extrêmes. Champ Psychosomatique, 3(35), 89-104.

Douville, O. (2005). Santé mentale et sécurisation psychique. L'Homme et la Société, 1(155), 129158. Recuperado de http://www.cairn.info/revue-1-homme-et-la-societe-2005-1-page-129. htm

Douville, O. (2012). Clinique psychanalytique de l'exclusion. Paris: Dunod.

Escande, C. (2005). Pourquoi des toxicomanes meurent? Le Carnet Psy, (103), 27-28.

Escande, P. (2002). Passions des drogues: la figure $d u$ ravage. Toulouse: Erès.

Freud, S. (1923/1981). Le Moi et le ça. En Essais de psychanalyse (pp. 219-274). Paris: Payot.

Gaspard, J.-L. (2007). Toxicomanía: complexo familiar e figura do pai. Psicologia em Revista, 13(2), 243-252.

Gaspard, J.-L (2014). La souffrance de l'être: formes modernes et traitements. Toulouse: Erès.

Gaspard, J.-L. \& Doucet C. (2009). Pratiques et usages du corps dans notre modernité. Toulouse: Erès. 
Gomart, E. (2004). Surprised by Methadone: In praise of drug substitution treatment in a French clinic. Body and Society, 10(2/3), 85-110.

Gori, R. \& Del Volgo, M.-J. (2005). La Santé totalitaire: Essai sur la médicalisation de l'existence. Paris: Denoël.

Gutiérrez, J. (1967). Infancia de la miseria. Bogotá: Timana.

Gutiérrez, J. (1972). Gamín: un ser olvidado. México: McGraw-Hill.

Gutiérrez, J. (2002). El camino de las muchas vueltas. Bogotá: Spiridon.

Hellebois, P. (2008). A quoi sert un corps? Cause freudienne, 69. Paris: Navarin.

Hesnard, A. \& Laforgue R. (1931). Les Processus d'auto-punition en psychologie des névroses et des psychoses, en psychologie criminelle et en pathologie générale. Paris: Denoël et Steele.

Jacques, J. P. (1997). Pour en finir avec les toxicomanies: Psychanalyse et pourvoyance légalisée des drogues. Belgique: De Boech Université.

Lacan, J. (1975-1976/2005). Le sinthome: le séminaire Livre XXIII. Paris: Seuil.

La Rosa, E. (1998). Santé, précarité et exclusion. Paris: PUF.

Lebrun, J. P. (2009). Un monde sans limite. Paris: Erès.

Melman, C. (2002). L'Homme sans gravité. Paris: Denoël.

Melman, C. \& Lebrun, J.-P. (2009). La nouvelle économie psychique: La façon de penser et de jouir aujourd'hui. Toulouse: Erès.
Miller, J.-A. (2004). Pièces détachées, Cours $n^{\circ} 1$ 17/11/2004 - 2. Recuperado de http://www. scribd.com/doc/166445600/J-A-Miller-Piecesdetachees-Cours-2004-2005

Olievenstein, C. (1982). La vie du toxicomane: Séminaire de l'Hôpital Marmottan. Paris: PUF.

Parizot, I. (2003). Soigner les exclus. Paris: PUF.

Patton, M.-Q. (1990). Qualitative research and evaluation methods. San Francisco: Sage.

Recalcati, M. (2005). Lignes pour une clinique des monosymptômes. La Cause Freudienne, Applications de la psychanalyse (Novembre), 83-97.

Rivera-Largacha, S. \& de Neuter, P. (2008). La consommation compulsive de drogues comme tentative de se séparer d'une jouissance archaïque. Cahiers de Psychologie Clinique, 2(31), 179198.

Rivera-Largacha, S. \& Gaspard, J.-L. (2010). Le recours aux drogues: actualité du rite dans notre modernité. Pratiques Psychologiques, 16(3), 249-257.

Roelens, T. (2001). De l'Eldorado au desechable. Sud/Nord, 2(15), 115-126. Recuperado de http:// www.cairn.info/revue-sud-nord-20012-page-115.htm

Sauret, M.-J. (2008). L'effet révolutionnaire du symptôme. Toulouse: PUM.

Spitz, R. A. (1968). De la naissance à la parole. La première année de la vie. Paris: PUF.

Zafiropoulos, M. (1988). Le toxicomane n'existe pas. Paris: Navarin.
Fecha de recepción: 25 de julio de 2014 fecha de aceptación: 22 de julio de 2015 